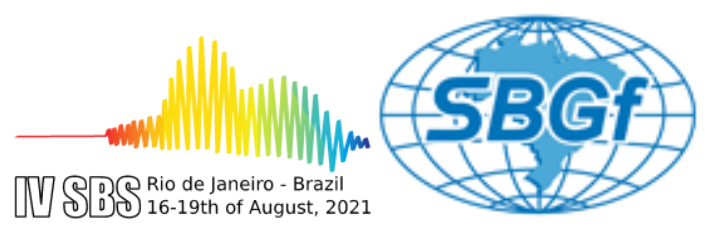

\title{
Preliminary analysis of infrasound generated by the meteoroid explosion over Japan on November 29, 2020 detected by IMS stations
}

Diogo Farrapo Albuquerque, Lucas Vieira Barros, Brandow Lee Neri, Matheus Fernandes da Cruz and Darlan Portela Fontenele, University of Brasília (UnB).

\section{Copyright 2021, SBGf - Sociedade Brasileira de Geofísica}

This paper was prepared for presentation during the $17^{\text {th }}$ International Congress of the Brazilian Geophysical Society held in Rio de Janeiro, Brazil, 16-19 August 2021.

Contents of this paper were reviewed by the Technical Committee of the $17^{\text {th }}$ International Congress of the Brazilian Geophysical Society and do not necessarily represent any position of the SBGf, its officers or members. Electronic reproduction or storage of any part of this paper for commercial purposes without the written consent of the Brazilian Geophysical Society is prohibited.

\begin{abstract}
The explosive fragmentation of large meteoroids is one of the strongest sources of infrasonic waves. In the absence of nuclear tests since 1980, bolide explosions are now the strongest infrasound sources available to calibrate and test the sensitivity of the International Monitoring System (IMS) infrasound instruments. Besides, it is important to detect meteoroid explosions using infrasound arrays to estimate their potential destruction and the frequency of occurrence. In order to extract wave attributes that may be used to test the sensitivity of IMS instruments, we applied the Progressive Multi-Channel Cross-correlation (PMCC) to the infrasound records generated by the meteoroid explosion over Japan on November 29, 2020. We obtained reliable results for only two stations: I30JP (Japan) and 145RU (Russia). The PMCC algorithm returned one family of 107 pixels with a mean backazimuth of $243.3 \pm 1.3^{\circ}$ for I30JP and 344 pixels with $160.6 \pm 1.0^{\circ}$ for $145 \mathrm{RU}$. The meteoroid explosion was located near to Shingu, Japan, with a yield of less than 1 $\mathrm{kt}$, which suggests that events generating energies $<1 \mathrm{kt}$ should be detected by IMS.
\end{abstract}

\section{Introduction}

Our planet is continuously bombarded by meteoroids of different sizes, ranging from dust grains to hundreds of meters in diameter. Although rarer, the latter group has the potential to cause mass extinctions and long term climate perturbations (Silber and Brown, 2019). Meteors are the luminous effect caused by ionization of the material due to collision with atmosphere. Meteorites are the fragments that makes to the Earth's surface (Matsuura and Picazzio, 2003; Pilger et al., 2019).

The explosive fragmentation of large meteoroids is one of the strongest sources of infrasonic waves. The most energetic event ever recorded by the International Monitoring System (IMS) was the 2013 Chelyabinsk bolide, quantified having an equivalent explosive yield of up to $500 \mathrm{kt}$ of TNT. The infrasonic waves generated by the explosion were detected by infrasound stations at long orthodrome distances (above 20,000 km) and after complete circumnavigations of the globe (up to 87,000 km) (Pilger et al., 2019).
The IMS was built to monitor nuclear tests in the atmosphere, on the surface and in the underground for the implementation of the Comprehensive Test Ban Treaty (CTBT). The IMS comprises 302 certified facilities for seismic, hydroacoustic, infrasound and radionuclide monitoring. The infrasound network is composed of 60 stations (53 certified), distributed uniformly around the globe (Figure 1), and focused on the detection of nuclear explosions in the atmosphere to verify compliance with the CTBT. It has been designed to detect and locate atmospheric nuclear explosions with a yield equivalent to one-kiloton of TNT reliably (Christie, 2007; Marty, 2019).

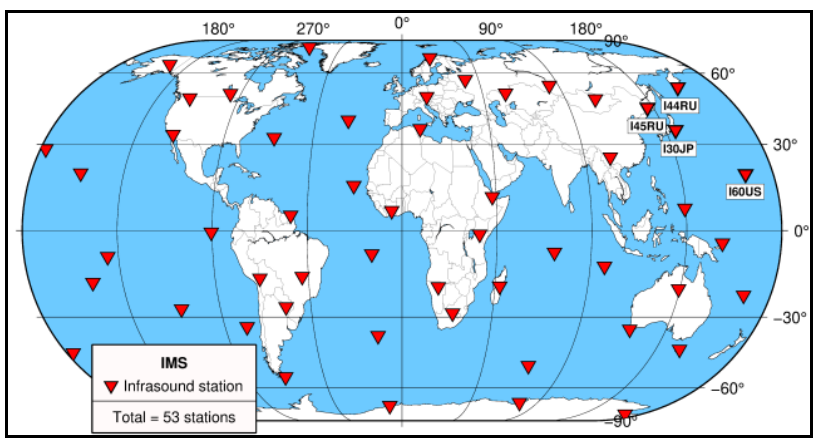

Figure 1 - International Monitoring System (IMS) certified infrasound stations. The stations used in this study are indicated by their codes: 144RU and I45RU (Russia), I30JP (Japan) and I60US (United States territory of Wake Island).

Since the last atmospheric nuclear explosion was conducted in 1980, bolide explosions are now the strongest infrasound sources available to calibrate and test the sensitivity of IMS infrasound instruments. Then it is important to detect meteoroid explosions using infrasound arrays to estimate their potential destruction, the frequency of occurrence and test the sensitivity of instruments. In this sense, the main objective of this work is to analyze the infrasonic waves generated by the meteoroid explosion that occurred over Japan on 29 November 2020 at about 2:00 in order to extract wave attributes that may be used to test the sensitivity of IMS infrasound network.

\section{Data}

Member States have access to all data deriving from the global verification regime built to monitor compliance with the CTBT. Raw and processed data are available to the members upon request to the International Data Centre (IDC) located in Vienna, Austria. The data used in this study was requested by the Seismological Observatory of 
University of Brasilia (SIS-UnB), which is one of the institutions in Brazil that operates infrasound and seismic stations to monitor possible nuclear tests in South America (Barros et al., 2020).

The meteor was seen by inhabitants of Japan on $11 / 29 / 2020$ at about 01:34 (local time). There were reports of the explosion in, at least, 14 Japanese cities: Yamaguchi, Okayama, Shizuoka, Kyoto (Figure 2), Yokkaichi, Toyahashi, Nagoya, Shima, Ainan, Bizen, Gifu, Kobe, Yonago and Tokushima. There was no report of this meteor outside Japan. Hence, using the sighting times as reference, we requested 24 hours of infrasound data relative to the day $11 / 28 / 2020$ (UTC), recorded by the nearest IMS stations.
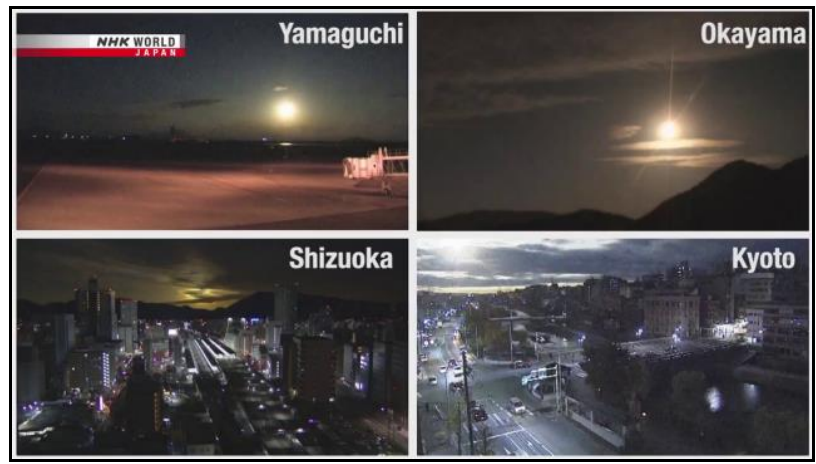

Figure 2 - Images provided by Japan Broadcasting Corporation (NHK) of the meteoroid explosion over Japan on November, 292020 at about 01:34 (local time). The meteor was seen in many cities, including Yamaguchi, Okayama, Shizuoka and Kyoto.

Two stations are located in Russia (144RU and 145RU), one in Japan (I30JP) and another in the United States territory of Wake Island (I60US). Very sensitive microbarometers were installed in the IMS infrasound stations, with digital recording, automated signal processing and reporting. We used two stations with 4 array elements (I44RU and I45RU), one with 6 (I30JP) and one with 8 (I60US) (Figures 3 and 4).

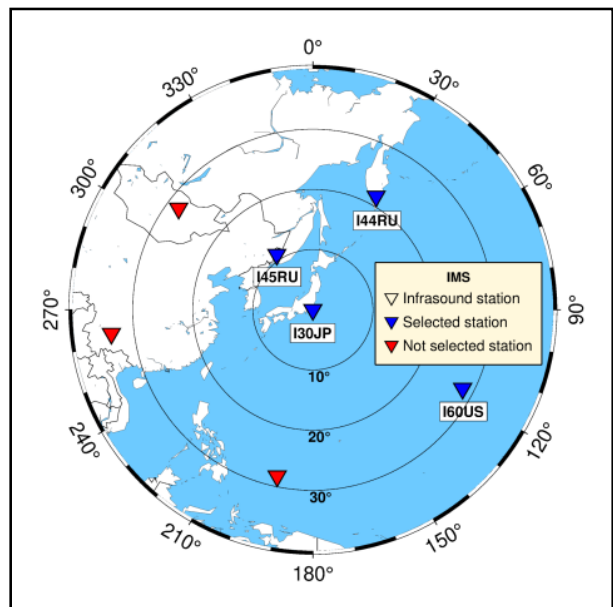

Figure 3 - Location of IMS infrasound stations used in this study. The concentric lines indicate the distance from the station I30JP.

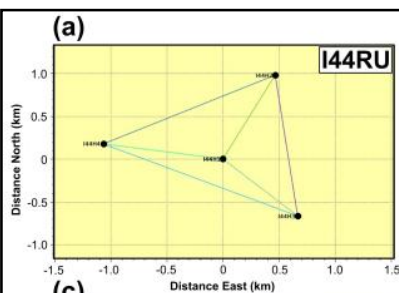

(c)
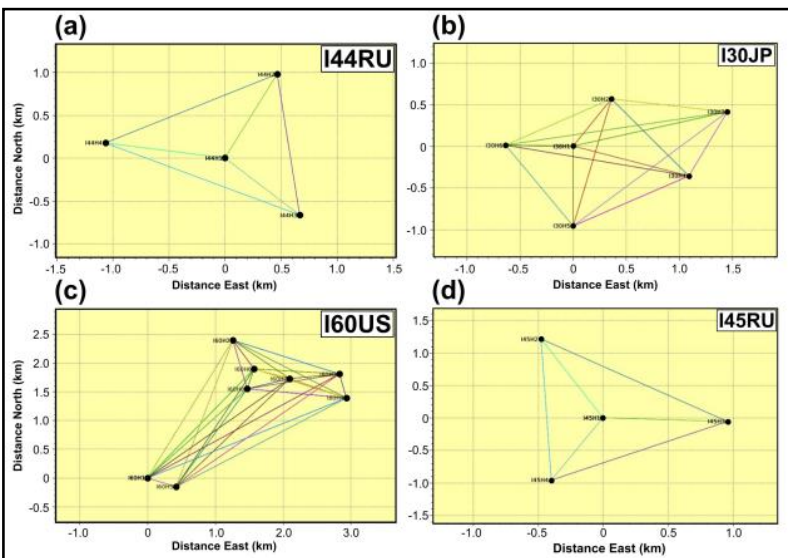

(d)

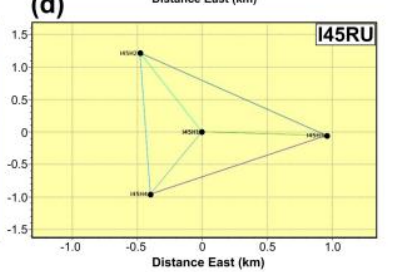

Figure 4-Elements of the array geometry of the stations indicated in the Figure 3 (blue triangles): (a) I44RU, (b) I30JP, (c) I60US and (d) I45RU.

\section{Method}

Sound waves are produced by compression and rarefaction of gases in the atmosphere. They are elastic longitudinal waves of which the particle motion is in the same direction as the wave propagation. To become audible to humans, sound waves must be in the frequency range of $20 \mathrm{~Hz}$ to $20 \mathrm{kHz}$. Frequencies lower than $20 \mathrm{~Hz}$ are inaudible to humans and are called infrasound, which is considered at $0.002 \mathrm{~Hz}$ (Evers and Haak, 2010).

Infrasonic waves travel with the speed of sound $(0.343$ $\mathrm{km} / \mathrm{s}$ at $20{ }^{\circ} \mathrm{C}$ ) in the air near to Earth's surface and have amplitudes in the order of $10^{-2} \mathrm{~Pa}$ to $10^{2} \mathrm{~Pa}$ at the receiver, after having traveled for hundreds to thousands of kilometers. They are affected by composition, wind velocity and temperature structure of the atmosphere. The absorption of sound in the atmosphere is a function of frequency and decreases with decreasing frequency. Then infrasound is capable of propagating over very long distances in the atmosphere due to its low attenuation (Evers and Haak, 2010; Silber and Brown, 2019).

Infrasound is generated by the displacement of large volumes of air, in other words, the sources are generally large and powerful. A large variety of natural and manmade sources are capable of producing infrasonic waves. Among the artificial sources, there are quarry blasts, rocket launches, supersonic aircrafts, nuclear explosions, oil and gas refinery flares, hydroelectric dams, wind generators and other cultural sources. The main natural sources of infrasound are: aurora, avalanches, earthquakes, lightning, oceanic waves, severe weather, volcanoes and meteors (Campus and Christie, 2010; Evers, 2009).

One of the most widely methods used to analyze infrasonic waves is the Progressive Multi-Channel Correlation (PMCC). This is the underground and atmospheric detection method of choice for IMS monitoring community that seeks to ensure compliance with CTBT (Runco Jr. et al., 2014). PMCC algorithm was originally designed by Cansi (1995) for seismic arrays and 
proved to be efficient at detecting low-amplitude, coherent infrasonic signals within incoherent noise.

PMCC is a correlation detector used to estimate wavefront parameters of coherent plane waves for a given time window using correlation time delays between successive array element triplets. The algorithm computes wave attributes, such as back-azimuth, trace velocity, frequency and root-mean-square amplitude, from band-pass filtering, cross-correlating data from station channels to aggregating time-frequency signal features to improve the signal-to-noise ratio (Mialle et al., 2019). PMCC allows detected signals to be grouped based on their similarities into families, which can be used to distinguish infrasonic sources (Taisne et al., 2019). This processing is performed consecutively in several frequency bands and in adjacent time windows covering the whole signal (Cansi, 1995; Cansi and Klinger, 1997; Runco Jr. et al., 2014).

We used DTK-GPMCC software, which is the graphic user interface of PMCC implemented in DASE Tool Kit, developed by the French National Data Center (CEA/DASE). DTK-GPMCC is the operational detector and viewer used to process infrasound data at the IDC (Mialle et al., 2019) and is provided by CTBTO to State Members through the National Data Centre in a box project (NDC-in-a-box) (Commissariat à l'énergie atomique et aux énergies alternatives, 2016).

We configured the DTK-GPMCC detection using 11 passband filters with a minimum frequency of the first band equal to $0.07 \mathrm{~Hz}$ and maximum frequency of the last band equal to $4.0 \mathrm{~Hz}$. The computation was performed considering a combination of 3 array elements to define a subnet.

The arrival time of infrasound was calculated using the 3 criteria: the time of meteor sightings, the speed of sound of $0.343 \mathrm{~km} / \mathrm{s}$ and the approximate distance of each station from the sighting locations. We located the infrasound source by triangulating the back-azimuths computed by PMCC for different stations.

\section{Results}

We analyzed data from 4 stations, but we obtained reliable results for only two: I30JP (Japan) and I45RU (Russia). The estimates of mean back-azimuth (BAZ), wave speed $(\mathrm{km} / \mathrm{s})$ and mean frequency, computed by DTK-GPMCC, are presented in the Table 1. Figures 5 to 8 present the pixel families indicating the back-azimuth and the speed variation of the infrasonic waves recorded by I30JP and I45RU stations.

Table 1 - Wave attributes estimated by DTK-GPMCC.

\begin{tabular}{cccc}
\hline Station & $\begin{array}{c}\text { Mean BAZ } \\
(\mathbf{(})\end{array}$ & $\begin{array}{c}\text { Mean speed } \\
(\mathbf{k m} / \mathbf{s})\end{array}$ & $\begin{array}{c}\text { Mean freq. } \\
(\mathbf{H z})\end{array}$ \\
\hline I30JP & $243.3 \pm 1.3$ & $0.368 \pm 0.012$ & $1.324 \pm 0.731$ \\
I45RU & $160.6 \pm 1.0$ & $0.322 \pm 0.002$ & $0.987 \pm 0.312$ \\
\hline
\end{tabular}

For 130JP data, the PMCC algorithm returned one family of 107 pixels with back-azimuth ranging from $237.748^{\circ}$ to $247.887^{\circ}$ (Figure 5a), wave speed ranging from 0.331 to $0.404 \mathrm{~km} / \mathrm{s}$ (Figure $5 \mathrm{~b}$ ) and frequency between 0.425 and $3.500 \mathrm{~Hz}$. The bolide infrasound arrival was recorded on $11 / 28 / 2020$ at $16: 59: 40$ (UTC) (Figure 5c). The backazimuth distribution and speed variation for I30JP data are presented by the rose diagram in Figure 6.

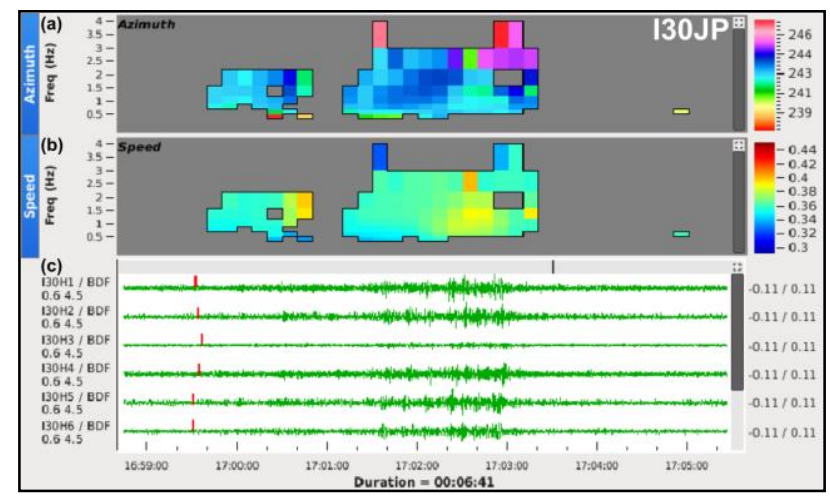

Figure 5 - (a) Pixel families of back-azimuths. The color scale indicates the back-azimuth variation in degrees. (b) Pixel families for infrasonic wave speed. The color scale indicates the velocity variation in $\mathrm{km} / \mathrm{s}$. (c) Infrasound recorded by 6 station elements $(\mathrm{I} 30 \mathrm{H} 1$ to $\mathrm{I} 30 \mathrm{H} 6)$. The first arrival on each element is indicated by the red vertical lines.

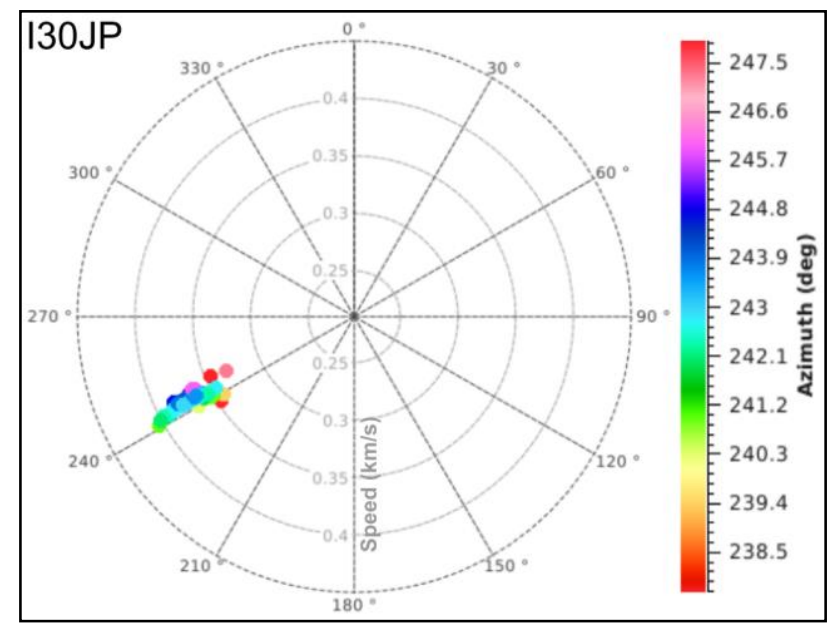

Figure 6 - Rose diagram of the back-azimuth distribution estimated by PMCC algorithm for the station I30JP. The vertical axis is the speed $(\mathrm{km} / \mathrm{s})$ and the color scale indicates the back-azimuth variation for each pixel.

For 145RU data, the PMCC algorithm returned one family of 344 pixels with back-azimuth ranging from $156.715^{\circ}$ to $162.330^{\circ}$ (Figure $7 \mathrm{a}$ ), wave speed ranging from 0.312 to $0.336 \mathrm{~km} / \mathrm{s}$ (Figure $7 \mathrm{~b}$ ) and frequency between 0.401 and $2.009 \mathrm{~Hz}$. The bolide infrasound arrival time was recorded at 17:45:12 (UTC) (Figure 7c). The back-azimuth distribution and speed variation for $145 \mathrm{RU}$ data are presented by the rose diagram in Figure 8. 


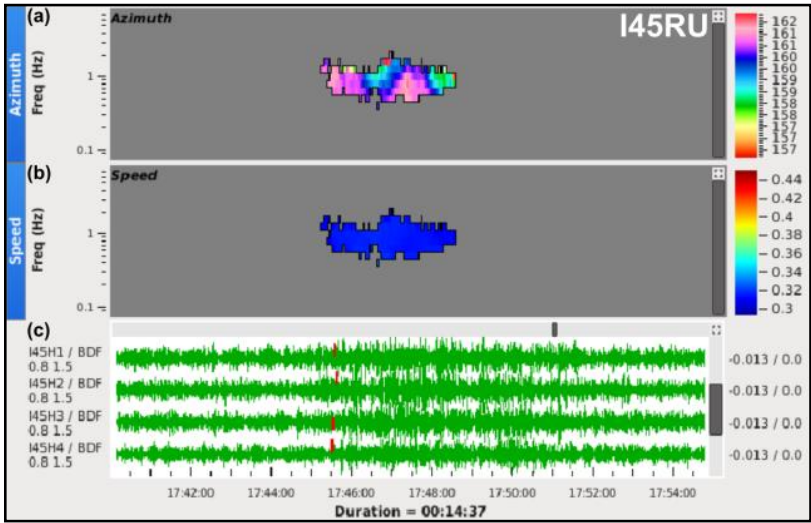

Figure 7 - (a) Pixel families of back-azimuths. The color scale indicates the back-azimuth variation in degrees. (b) Pixel families for infrasonic wave speed. The color scale indicates the velocity variation in $\mathrm{km} / \mathrm{s}$. (c) Infrasound recorded by 4 station elements ( $145 \mathrm{H} 1$ to $145 \mathrm{H} 4)$. The first arrival on each element is indicated by the red vertical lines.

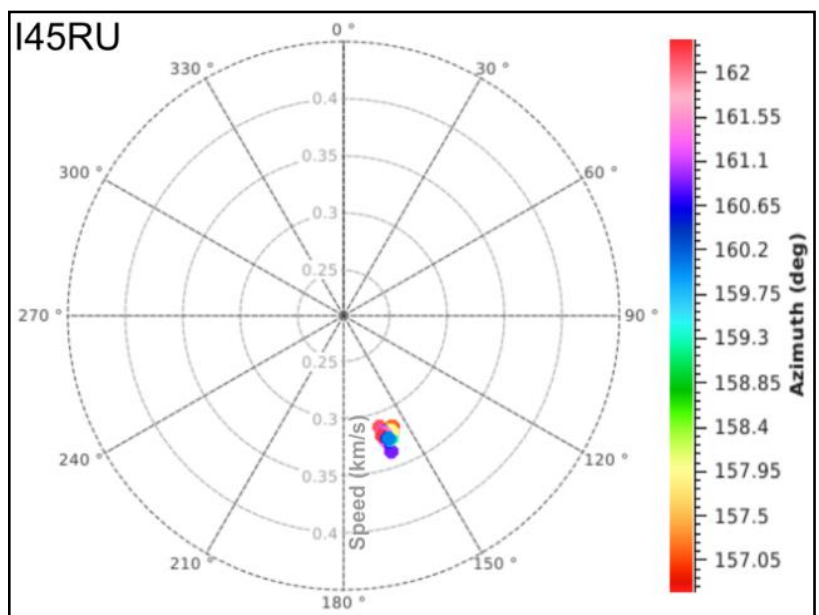

Figure 8 - Rose diagram showing the back-azimuth distribution estimated by PMCC algorithm for the station 145RU. The vertical axis is the speed $(\mathrm{km} / \mathrm{s})$ and the color scale indicates the back-azimuth variation for each pixel.

Triangulating the mean back-azimuths computed by PMCC for I30JP and I45RU stations (Table 1), we estimated the bolide explosion location near to Shingu, in the province of Wakayma, Japan (lat.: 33.6284, long: 136.451), as indicated by yellow star in the Figure 9. Our estimation is corroborated by images, videos and sightings reported in the media, which are concentrated on the southwestern region of Japan (red squares in Figure 8).

Considering that $1 \mathrm{kt}$ bolides have a detection threshold of about 7,000 km (Ens et al., 2012) and the infrasound generated by the bolide explosion over Japan was recorded at a maximum distance of $1,237.9 \mathrm{~km}$ (station 145RU, Figure 8), it is possible to conclude that $11 / 29 / 2020$ bolide had a yield of less than $1 \mathrm{kt}$. Although the IMS infrasound network was designed to detect atmospheric explosions with a minimum yield of one- kiloton reliably, those facts suggest that it is possible to detect atmospheric explosions of much less than that.

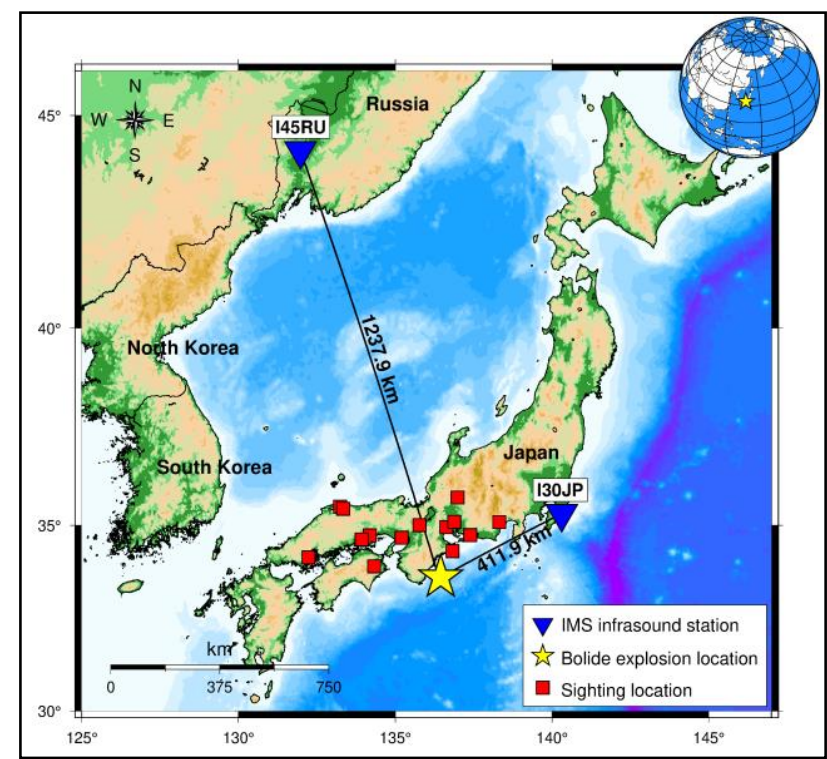

Figure 9 - Location of the meteoroid explosion and stations I30JP and I45RU. The lines connecting the stations to the bolide location indicate the distance.

\section{Conclusions}

From the 4 stations used in this study, we obtained reliable results for only two: I30JP (Japan) and I45RU (Russia). The PMCC algorithm returned one family of 107 pixels with back-azimuth ranging from $237.748^{\circ}$ to $247.887^{\circ}$ (mean BAZ $=243.3 \pm 1.3^{\circ}$ ) for I30JP. In the case of I45RU, the algorithm resulted in one family of 344 pixels with back-azimuth ranging from $156.715^{\circ}$ to $162.330^{\circ}$ (mean $\mathrm{BAZ}=160.6 \pm 1.0^{\circ}$ ).

Using the mean BAZ estimated for I30JP and I45RU, we located the meteoroid explosion point near to Shingu, province of Wakayma, Japan (lat.: 33.6284, long.: 136.451). This location was corroborated by the sightings reported in many cities in the southwestern Japan.

Although the IMS infrasound network was designed to detect atmospheric explosions with a yield of $1 \mathrm{kt}$, our analysis indicates that the bolide explosion over Japan is of less than $1 \mathrm{kt}$, which suggests that events generating energies $<1 \mathrm{kt}$ TNT should be detected by IMS network.

\section{Acknowledgments}

This study was financed in part by the Coordenação de Aperfeiçoamento de Pessoal de Nível Superior - Brasil (CAPES) - Finance Code 001. The authors thank CTBTO and Seismological Observatory of University of Brasília for providing the infrasound data.

\section{References}

Barros, L.V., Neri, B.L., Carvalho, J.M. de, Fontenele, D.P., 2020. A participação brasileira na verificação do Tratado de Proibição Total de Testes Nucleares, 1st ed. 
Copiart, Tubarão.

Campus, P., Christie, D.R., 2010. Worldwide Observations of Infrasonic Waves, in: Infrasound Monitoring for Atmospheric Studies. Springer Netherlands, Dordrecht, pp. 185-234. https://doi.org/10.1007/978-1-4020-9508-5_6

Cansi, Y., 1995. An automatic seismic event processing for detection and location: The P.M.C.C. Method. Geophys. Res. Lett. 22, 1021-1024. https://doi.org/10.1029/95GL00468

Cansi, Y., Klinger, Y., 1997. An automated data processing method for mini-arrays. CSEM/EMSC Newsl. 11, 1021-1024.

Christie, D.R., 2007. Recent developments in infrasound monitoring technology: application to CTBT verification. CTBTO Spectr. 18-24.

Commissariat à l'énergie atomique et aux énergies alternatives, 2016. DASE TOOL KIT (DTK-GPMCC).

Ens, T.A., Brown, P.G., Edwards, W.N., Silber, E.A., 2012. Infrasound production by bolides: A global statistical study. J. Atmos. Solar-Terrestrial Phys. 80, 208-229. https://doi.org/10.1016/j.jastp.2012.01.018

Evers, L.G., 2009. Acoustic remote sensing of the atmosphere. Technische Universiteit Delft, Delf.

Evers, L.G., Haak, H.W., 2010. The Characteristics of Infrasound, its Propagation and Some Early History, in: Infrasound Monitoring for Atmospheric Studies. Springer Netherlands, Dordrecht, pp. 3-27. https://doi.org/10.1007/978-1-4020-9508-5_1

Marty, J., 2019. The IMS Infrasound Network: Current Status and Technological Developments, in: Infrasound Monitoring for Atmospheric Studies. Springer International Publishing, Cham, pp. 3-62. https://doi.org/10.1007/9783-319-75140-5 1

Matsuura, O.T., Picazzio, E., 2003. O Sistema Solar, in: Astronomia: Uma Visão Geral Do Universo. Edusp, São Paulo, p. 288.

Mialle, P., Brown, D., Arora, N., 2019. Advances in Operational Processing at the International Data Centre, in: Infrasound Monitoring for Atmospheric Studies. Springer International Publishing, Cham, pp. 209-248. https://doi.org/10.1007/978-3-319-75140-5_6

Pilger, C., Ceranna, L., Le Pichon, A., Brown, P., 2019. Large Meteoroids as Global Infrasound Reference Events, in: Infrasound Monitoring for Atmospheric Studies. Springer International Publishing, Cham, pp. 451-470. https://doi.org/10.1007/978-3-319-75140-5_12

Runco Jr., A.M., Louthain, J.A., Clauter, D.A., 2014. Optimizing the PMCC Algorithm for Infrasound and Seismic Nuclear Treaty Monitoring. Open J. Acoust. 04, 204-213. https://doi.org/10.4236/oja.2014.44020

Silber, E., Brown, P., 2019. Infrasound Monitoring as a Tool to Characterize Impacting Near-Earth Objects (NEOs), in: Infrasound Monitoring for Atmospheric Studies. Springer International Publishing, Cham, pp. 939-986. https://doi.org/10.1007/978-3-319-75140-5_31
Taisne, B., Perttu, A., Tailpied, D., Caudron, C., Simonini, L., 2019. Atmospheric Controls on Ground- and SpaceBased Remote Detection of Volcanic Ash Injection into the Atmosphere, and Link to Early Warning Systems for Aviation Hazard Mitigation, in: Infrasound Monitoring for Atmospheric Studies. Springer International Publishing, Cham, pp. 1079-1105. https://doi.org/10.1007/978-3-31975140-5_34 